\title{
OS DEZ MANDAMENTOS DO SÍNODO ESPECIAL PARA A AMAZÔNIA
}

\section{Ten Commandments of the Special Synod for the Amazon}

Ima Célia Guimarães Vieira (Museu Paraense Emilio Goeldi - MPEG) ORCID iD: https://orcid.org/0000-0003-1233-318X

Márcia Maria de Oliveira (Universidade Federal de Roraima - UFRR) LATTES iD: http://lattes.cnpq.br/8199304840769363

Raimundo Posidônio Carrera da Mata (Faculdade Católica de Belém - FACBEL)

Informações do artigo

Recebido em 10/02/2020 Aceito em 24/04/2020 https://doi.org/10.25247/2447-861X.2020.n249.pg-32

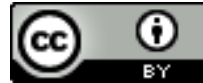

Esta obra está licenciada com uma Licença Creative Commons Atribuição 4.0 Internacional.

\section{Como ser citado (modelo ABNT)}

VIEIRA, Ima Célia G.; OLIVEIRA, Márcia Maria de; MATA, Raimundo Posidônio C. da. Os Dez Mandamentos do Sínodo Especial para a Amazônia. Cadernos do CEAS: Revista Crítica de Humanidades. Salvador, v. 45, n. 249, p. 9-33, jan./abr. 2020. DOI: https://doi.org/10.25247/2447-

861X.2020.n249.pg-32

\begin{abstract}
Resumo
Este artigo representa uma contribuição direta dos trabalhos sinodais, a partir do Sínodo Especial para a Amazônia, realizado no Vaticano em outubro de 2019. Apresenta-se uma breve descrição dos caminhos sinodais desde a encíclica Laudato Sì, com o intento de caracterizar o método e a abordagem usada na reunião dos bispos. Os principais resultados do Sínodo para a Amazônia são descritos brevemente e, em seguida, elencamos os seus Dez Mandamentos, considerando os aspectos mais relevantes discutidos nesta reunião e que integram a voz da Amazônia com a voz e o sentimento dos participantes do Sínodo. Argumenta-se, ao final, que o cuidado da Casa Comum deve garantir que os Dez Mandamentos sejam uma constante nas açōes de uma Igreja profética, aliada dos povos da Amazônia.
\end{abstract}

Palavras-chave: Sinodalidade. Amazônia. Mandamentos. Conversão Integral.

\section{Abstract}

This article represents a direct contribution of the synodal process from the Special Synod for the Amazon, held in the Vatican in October 2019. A brief description of the synodal paths since the encyclical Laudato $\mathrm{Si}$ is presented, with the intention of characterizing the method and the approach used in the bishops meeting. The main results of the Synod for the Amazon are briefly described and then we list its Ten Commandments, considering the most relevant aspects discussed at this meeting and which integrate the voice of the Amazon with the voice and sentiment of the participants in the Synod. In the end, it is argued that formally for the care of the Common House, must ensure that the Ten Commandments are a constant in the actions of a prophetic Church, allied with the peoples of the Amazon.

Keywords: Synodality. Amazon. Commandments. Integral Conversion. 


\section{Introdução}

A Amazônia é considerada uma região estratégica de onde poderão surgir respostas aos graves problemas que assolam a sociedade mundial (PERANI, 2018). No contexto nacional e internacional, a região tem sido foco de atenção tanto da Igreja como da sociedade mundial.

A partir do Concílio Vaticano II e o caminho sinodal de Medellín e Puebla foram formuladas importantes diretrizes com vigor profético em defesa dos indígenas e dos pobres. Mas, foi a partir dos anos 70, que a Igreja passou a ter uma voz profética e sintonizada com os apelos dos povos amazônicos (MATA, 2007). Neste aspecto, foi fundamental e norteador o Documento de Santarém, produzido pelos Bispos em 1972 (MATA, 2016), que apresenta um modelo de Igreja mais ministerial e sugere uma evangelização com abrangência harmoniosa com todos os homens, o indivíduo e a sociedade, sem dicotomias (PERANI, 2018). Por outro lado, o envolvimento da Igreja com as questões ambientais ganha importância no trabalho das Comunidades Eclesiais de Base, no combate ao desmatamento e na garantia das formas de subsistência para os povos da floresta.

A partir de 2015, com a Encíclica Laudato Si, o Papa Francisco difunde uma perspectiva ecológica mais abrangente, uma "ecologia integral", pois "são inseparáveis a preocupação pela natureza, a justiça para com os pobres, o empenho na sociedade e a paz interior" (LAUDATO Sì, 2015: 4, \$10) e nos remete à inseparável relação existente entre as questões social e ambiental. A Igreja se coloca no campo ecológico como um ator de alcance internacional, que poderia ajudar a gerar uma conscientização mundial em prol do compromisso com o meio ambiente, inclusive da Amazônia, onde os problemas ambientais pesam, sobretudo, sobre os povos tradicionais e indígenas.

Desde a publicação da Laudato Si até a Assembleia Sinodal passaram-se quatro anos. No meio do caminho, a sinodalidade esteve presente. Foram 260 escutas, com o envolvimento de 87 mil pessoas $^{1}$. O documento preparatório do Sínodo para a Amazônia, lançado em junho de 2018 , destaca com vigor as múltiplas ameaças que pesam sobre os povos indígenas, as comunidades tradicionais (quilombolas, seringueiros e ribeirinhos) e os

\footnotetext{
1 Síntese Repam em português disponível em: http://repam.org.br/wp-content/uploads/2019/07/Informeproceso-consulta-sinodal-Portugues.pdf. Acesso em 20 jan. 2020.
} 
camponeses da Amazônia, especialmente vulneráveis ante a expansão de grandes projetos extrativos, que atacam sua identidade e mesmo sua sobrevivência. "Hoje, os povos indígenas estão ameaçados em sua existência física, cultural e espiritual" (INSTRUMENTUM LABORIS, 2019, n. 90).

Neste contexto, há o reconhecimento de que o Sínodo para a Amazônia inaugura um novo tempo para a Igreja. O tempo do escutar, refletir e agir, pois a Amazônia não pode esperar. O Papa Francisco e os 282 participantes do Sínodo especial para a Amazônia reuniram-se no Vaticano no período de 6 a 27 de outubro de 2019, sob o lema Amazônia: Novos Caminhos para a Igreja e para uma Ecologia Integrada, a fim de realizar um diagnóstico e propor os caminhos da Igreja para uma das mais complexas, diversificadas e desafiadoras regiões do mundo, ameaçada pela cobiça e ganância de interesses internos e externos. Uma região com seus recursos hídricos, florestais e do subsolo em permanente exploração desde a colonização, o que culmina com a destruição de povos, culturas e saberes ancestrais.

A sinodalidade foi o fio condutor da Assembleia Sinodal e o caminho do discernimento dos padres sinodais, sob a guia do Papa Francisco, para escutar a realidade, discernir o que Deus diz através da realidade, à luz de sua Palavra, do Espírito Santo e, depois, agir. A Assembleia Sinodal foi também um espaço de escuta e reflexão em debates simultâneos realizados em doze subgrupos de trabalhos denominados 'Círculos Menores', organizados nas línguas portuguesa, espanhola, italiana e inglesa/francesa.

Neste artigo, apresentamos uma breve caracterização dos caminhos e experiências sinodais e extraímos a essência do Documento Final da Assembleia Sinodal, dividido em cinco capítulos e 120 parágrafos, para apontar os dez mandamentos do Sínodo da Amazônia, a partir da nossa experiência como peritas/os².

\section{A Encíclica Laudato Si e o Sínodo para a Amazônia}

Da Encíclica Laudato Si (2015) aprendemos que "tudo está interligado". Esta frase do Papa Francisco demonstra a importância de uma noção fundamental para compreender a

2 Definição da Secretaria Sinodal do Vaticano para o Grupo de Trabalho responsável pela sistematização de todo material elaborado durante a Assembleia Sinodal. A equipe contou com 25 especialistas ( 20 homens e 05 mulheres) de diversos países, a maioria doutores/as, nas áreas da teologia, ecologia, sociologia, História da Igreja, eclesiologia, antropologia, dentre outras. 
vida e o valor da natureza, e aumentar a consciência ecológica no planeta, a interligação, a interdependência entre todos os seres e as coisas. Na sociedade, indivíduos e grupos se organizam e se inter-relacionam para construir uma existência coletiva e forjar a sua história. Na religião, as criaturas e a criação são entes que formam as partes de um todo que abrange a humanidade, as formas de vida e o próprio planeta.

O processo sinodal retomou o apelo da Laudato Si (2015) pela substituição do estilo de vida consumista por um modo de vida simples e sustentável, que tem como referência o conceito da Ecologia Integral, que abarca as dimensões humana, social e ambiental e sua interdependência, com vistas a defender a unificação da humanidade contra a degradação ambiental, a destruição de culturas e povos e as mudanças climáticas (LAUDATO Sì, 2015).

$\mathrm{Na}$ parte introdutória da Laudato Si (2015, p. 3), o Papa Francisco afirma que "esquecemo-nos de que nós mesmos somos terra (cf. Gn 2, 7). O nosso corpo é constituído pelos elementos do planeta; o seu ar permite-nos respirar, e a sua água vivifica-nos e restaura-nos". E chama a atenção de toda a sociedade para a "comunhão universal" acenando para a interligação entre tudo e todos na grande casa comum (LAUDATO Sì, 2015, p. 3).

À luz da Laudato Si'o processo sinodal nos fez entender que, para cuidar da casa comum, primeiramente temos que cuidar de nós mesmos. Enquanto permitirmos que permaneçam as desigualdades, as injustiças e a violação aos direitos humanos uns dos outros, não teremos condições de lutar e defender os outros seres universais com os quais estamos interligados. Entendemos que a aliança entre os seres humanos e a convivência planetária começa por cada um, cada uma, parte de uma atitude pessoal e, ao mesmo tempo, coletiva, que estabelece alianças entre nós e, simultaneamente, entre todos os outros seres ao nosso redor.

As escutas realizadas na primeira fase do processo sinodal esclarecem que a experiência milenar dos Povos Ameríndios representa um caminho possível de convivência e inter-relação na casa comum. Cuidar da casa comum implica cuidar primeiramente uns dos outros numa atitude de respeito pela vida e pela dignidade de cada um(a) e de todos(as) simultaneamente. Este parece ser um princípio ancestral dos Povos da Amazônia. Assim dizem os mais velhos: "Nós somos parte da terra, a terra é parte de nós. Um é a extensão do outro, nós não vivemos a sós". A consciência da convivência na interdependência é o princípio 
do respeito e do cuidado: "se nós cuidarmos da terra, a terra cuida de nós"3 (OLIVEIRA, 2017, p. 14).

No processo sinodal, as comunidades do campo e das cidades aprenderam com os povos indígenas uma das questões centrais no princípio do cuidado, apresentado na Laudato $S i$, que é a atitude de respeito para com todos os seres planetários. Os povos indígenas nos ensinam que o respeito não é sinônimo de temor. Não se respeita por medo. Se respeita por amor. Este princípio universal do cuidado por amor estabelece as bases da relação proporcional entre humanos e natureza, ambos criados como extensão do amor de Deus Criador. O cuidado da terra pelo homem/mulher é proporcional ao cuidado do homem/mulher pela terra. Estabelece-se, então, o princípio da inter-relação, que é a base da convivência na casa comum, na prática da "ecologia integral vivida com alegria e autenticidade" e invocada pela Laudato Si' (2015, p. 10) como grande legado de São Francisco de Assis. A este respeito, o Papa Francisco nos alerta que a "destruição do ambiente humano é um fato muito grave, porque, por um lado, Deus confiou o mundo ao ser humano e, por outro, a própria vida humana é um dom que deve ser protegido de várias formas de degradação. Toda a pretensão de cuidar e melhorar o mundo requer mudanças profundas nos estilos de vida" (LAUDATO SI', 2015, p. 4).

No processo sinodal compreendemos que "o urgente desafio de proteger a nossa casa comum inclui a preocupação de unir toda a família humana na busca de um desenvolvimento sustentável e integral, pois sabemos que as coisas podem mudar" (LAUDATO Sì, 2015, p. 12). Deparamo-nos com dois paradigmas de desenvolvimento em conflito na Amazônia. Por um lado, os povos indígenas nos ensinam que desenvolvimento significa o "envolvimento" de todos e todas para a garantia da sobrevivência em condições plenas numa convivência baseada na relação de respeito e interdependência com a natureza sem prejuízos para nenhuma das partes. Por outro lado, a Amazônia está sendo bombardeada por projetos desenvolvimentistas comprometidos com o avanço da economia, a dominação e o controle da exploração comercial dos recursos naturais inseridos no grande mercado internacional (OLIVEIRA, 2017).

3 Fragmento da letra da música Cuidar da Terra do grupo Imbaúba, composição dos músicos amazonenses Celdo Braga e Candinho. Faixa 13 do Álbum do Grupo Imbaúba e Celdo Braga - Verde (2012). 
Atualmente, na Amazônia, muitos são os focos de resistência aos projetos desenvolvimentistas pautados na exploração desmedida e na destruição dos recursos naturais que, no entendimento dos Povos da Amazônia, seriam recursos de uso coletivo compartilhado, num modo de vida não capitalista, adotado e assimilado milenarmente por esses povos. Nesse entendimento, o Bem Viver não significa ausência do progresso e nem atraso proposital. Pelo contrário. Significa alternativa ao desenvolvimento baseado na lógica desenvolvimentista neoliberal ou neocolonial. É a comprovação de outro mundo possível. Não se trata de rechaço à ciência e às novas tecnologias. As alternativas à sociedade neoliberal, ao mercado e ao consumo exacerbado podem contar com as inovações tecnológicas de ponta, desde que estejam a serviço da vida com qualidade e dignidade para todos os seres vivos sobre a terra (OLIVEIRA, 2019). Conclui-se, assim, que o Sínodo para a Amazônia representa uma iniciativa consciente da Igreja de implementar a Laudato Si (HUMMES, 2018).

Dada sua relevância, o Sínodo discutiu as possibilidades de uma ecologia integral e as lições de convivência e de cuidado com a criação que os povos indígenas ensinam para todo o planeta. Nesta perspectiva, conseguiu revelar uma "Igreja com rosto amazônico", com maneira própria de celebrar e viver a Palavra de Deus, com uma espiritualidade própria, com suas devoções e religiosidades (OLIVEIRA, 2019).

A primeira parte do processo sinodal, dedicada a 'ver e ouvir', possibilitou ver a identidade e os clamores do povo de Deus na Pan-Amazônia, de maneira especial dos Povos Indígenas com suas Identidades, processos históricos e as ameaças atuais. Contribuiu para conhecer a biodiversidade do território e do Bioma Amazônia para poder defender a região com suas florestas, águas e povos. Ajudou a ver e conhecer melhor a caracterização da diversidade sociocultural, política e econômica da Amazônia. Despertou a Igreja da PanAmazônia para a situação sociodemográfica e apontou o problema da concentração populacional nas cidades de forma precária (OLIVEIRA, 2019).

As atividades desenvolvidas na primeira fase do processo sinodal4, no segundo semestre de 2018, serviram para revisitar a memória histórica e eclesial dos Povos da Pan-

\footnotetext{
4 Além dos estudos sistematizados do Documento Preparatório, as dioceses e prelazias de toda Pan-Amazônia promoveram diversas modalidades de encontros e eventos nas bases para promover "ampla escuta do Povo de Deus". No final do processo de escuta foram organizados relatórios e informes e enviados à REPAM para
} 
Amazônia, reafirmar a justiça e os seus direitos, reforçar as práticas culturais, a espiritualidade e sabedoria dos povos dessa imensa região num profundo processo de pastoral e conversão ecológica, tendo em vista os novos caminhos para uma Igreja com Rosto Amazônico (INSTRUMENTUM LABORIS, 2019).

Depois que o Papa Francisco ouviu os povos indígenas em sua visita a Porto Maldonado, no Peru, em 19 de janeiro de 2018, o Sínodo ganhou novo impulso, transformando-se num instrumento de defesa da Amazônia e seus povos. A partir destas perspectivas, o Sínodo Especial para Amazônia passa a ter como tema "Amazônia: novos caminhos para a Igreja e por uma ecologia integral".

Dentre as várias temáticas estudadas e aprofundadas no processo sinodal, esteve em pauta o "rosto dos povos da Amazônia", que representa uma rica diversidade sociocultural em uma região gigantesca onde vivem povos e culturas diferentes, que ocupam a região com modos de vida distintos. E toda a riqueza natural de seus territórios está em risco mediante a exploração desmedida das grandes corporações econômicas (INSTRUMENTUM LABORIS, 2019). Também tiveram lugar, no debate do Sínodo, os camponeses e os ribeirinhos, povos amazônicos que, historicamente, se apropriaram dos territórios de várzea e da terra firme5, e utilizam os recursos naturais da várzea, tendo como pano de fundo o contínuo e cíclico movimento de seus rios e sofrem com a presença dos pescadores comerciais, predadores dos recursos que já se tornaram escassos em determinadas regiões. As comunidades quilombolas também foram lembradas no Sínodo porque integram um conjunto de povos que se encontra ameaçado pelos grandes projetos econômicos, pelo avanço do latifúndio e pelo permanente processo de desmatamento da floresta.

sistematização. É o que está disponível nos arquivos da REPAM para consulta pública, conforme informado na nota número 01 deste artigo.

5 Os territórios de várzea são aqueles localizados às margens dos rios e lagos, por isso seus habitantes são popularmente denominados 'ribeirinhos'. A terra firme é o território das florestas, especialmente os seringais que ocupam as reservas extrativistas. Essa modalidade de ocupação e uso do território ocorre somente na Amazônia brasileira, por isso, on Instrumentum Laboris não menciona a experiência das assim chamadas Comunidades Extrativistas da Amazônia brasileira vinculadas ao Sistema Nacional de Unidades de Conservação (SNUC - Lei nº 9.985/2000). As comunidades das Reservas Extrativistas (RESEX) são espaços territoriais protegidos cujo objetivo é a proteção dos meios de vida e a cultura de populações tradicionais, bem como assegurar o uso sustentável dos recursos naturais de áreas habitadas por seringueiros-camponeses extrativistas. O sustento destas populações se baseia no extrativismo e, de modo complementar, na agricultura de subsistência e na criação de animais de pequeno porte. 
O processo sinodal trouxe à tona o grande desafio da Igreja nas cidades. As complexidades atuais da "floresta urbanizada", como proposto por Becker (1995), têm evidenciado a multiplicidade de atores e processos atuantes na transformação do território e reforçam a necessidade de discutir o espaço urbano na Amazônia. Por isso, as cidades dos nove países que compõem a Pan-Amazônia, com seus desafios e perspectivas também foram amplamente abordadas no Sínodo. As cidades da Amazônia têm crescido muito rapidamente e recolhido muitos migrantes deslocados de forma compulsória, empurrados para as periferias de grandes centros urbanos que avançam floresta adentro (SAHTLER et al.2009). Na sua maioria, são povos indígenas, ribeirinhos, quilombolas expulsos pelos garimpos e mineradoras, encurralados pelas madeireiras, e machucados nos conflitos agrários e socioambientais resultantes da omissão falaciosa do Estado, que tem adotado um processo acelerado de esvaziamento de territórios estratégicos de grande interesse econômico, cobiçados por empresas nacionais e internacionais.

As grandes riquezas produzidas na Amazônia e a vastidão de seus bens econômicos são negados à maioria de seus habitantes, o que favorece a predominância das desigualdades sociais, econômicas, culturais e políticas. Nessa perspectiva, as cidades representam uma realidade marcada por grandes contradições: de um lado, uma vastidão enorme de terras e florestas. Por outro lado, há uma legião de empobrecidos no campo e nas cidades (OLIVEIRA, 2016, p. 77), sem acesso aos serviços básicos de infraestrutura como saneamento ambiental, atendimento de saúde e serviços de tratamento de água (SILVA, 2006).

\section{O processo sinodal e o verbo amazonizar}

Em pleno processo sinodal, as escutas realizadas em toda Pan-Amazônia durante a segunda metade de 2018, apontaram muitas novidades. Uma delas, foi a pertinência da reinvenção do verbo amazonizar. Trata-se de um novo vocábulo a ser incluído futuramente à gramática da língua portuguesa, graças a sua popularidade a partir do Sínodo para a Amazônia.

Até onde se sabe, o termo "amazonizando" foi usado pela primeira vez em 2005 (HECK; LOEBENS; CARVALHO, 2005) com o sentido de ter a Amazônia como tema indispensável por quem está preocupado com o futuro do planeta. Por sua vez, o termo "amazonizar" foi usado por Dom Moacyr Grechi , no artigo "Mutirão pela Amazônia: espírito 
missionário e sensibilização da sociedade" em 2005. Neste artigo, o bispo aponta a necessidade de a Igreja "amazonizar" o Brasil com ações de formação para a ecologia e de uma educação que eduque para a proteção ambiental, para a paz e solidariedade a partir da Amazônia.

Amazonizar é um verbo de ação, que indica, primeiramente, um extenso e intenso processo de estudo e conhecimento sobre a Amazônia. É preciso conhecer para amar, proteger e defender, evocam os clamores dos povos da Amazônia em praticamente todos os relatórios das Escutas Sinodais realizadas nas pequenas comunidades, nos fóruns amplos de debates nacionais e internacionais, nas assembleias territoriais realizadas em todas as dioceses e prelazias da Amazônia.

$\mathrm{Na}$ ressignificação do verbo amazonizar, apresenta-se a palavra com muitos significados, dependendo de onde é acionada e dos objetivos a que se propõe. No campo político, é uma resposta ao disparate economicista da internacionalização da Amazônia. Ao invés de internacionalizar a Amazônia, propõe-se concretamente amazonizar o mundo. Isso significa carregar o mundo de sentido, de sensibilidade, de contemplação, de admiração e comprometimento para com a obra da criação presente na exuberância da Amazônia. Evoca respeito às identidades culturais forjadas a partir da relação de respeito e de convivência com a natureza.

Nessa perspectiva, a terra, a floresta e os rios simbolizam o locus da organização social e política, lugar da produção e transmissão de práticas sustentáveis que se encontram em todos os lugares da Amazônia. Do latim, locus significa literalmente "lugar", "posição", "local". Representa o "lugar". Para os povos ameríndios, a Amazônia representa a sua casa coletiva, seu lugar por excelência. Para os Povos da Amazônia, a terra não é propriedade, é lugar e espaço vivencial. Não é terreno nem gleba que se negocia no mercado imobiliário. É locus e território imaginado, sentido e vivenciado. Lugar da memória e do respeito aos antepassados. É o lugar da agroecologia, do extrativismo responsável voltado para a sobrevivência, da pesca, da festa, dos jogos e danças tradicionais. Conviver com o bioma amazônico representa um grande desafio a ser reaprendido com os Povos Tradicionais da região, de maneira especial os povos indígenas, camponeses e ribeirinhos.

Em muitos contextos da Amazônia, o verbo amazonizar foi sendo evocado como memória de resistência a um processo intenso de violência praticado contra a Amazônia desde a colonização. Os relatos dos cronistas das primeiras viagens de portugueses e 
espanhóis, ao longo dos rios Solimões e Amazonas, nos séculos XVI e XVII, fazem inúmeras referências à abundância de alimentos que encontraram em todas as povoações, ao longo dos rios principais e de seus afluentes, à alta densidade populacional de numerosas "nações" que habitavam a região (DANIEL, 2004, v. 1-2). Projeções feitas a partir de documentos e de pesquisas arqueológicas (SOUZA et al, 2018) estimam a população indígena, antes da colonização, entre oito e dez milhões de indígenas somente na Amazônia. A perspectiva histórica desses povos foi interrompida de forma brusca e violenta pelo projeto colonial (PORRO, 2006) que, valendo-se da guerra, da escravidão, da ideologia religiosa e das doenças, provocou na Amazônia uma das maiores catástrofes demográficas da história da humanidade, além de um etnocídio sem precedentes (DANIEL, 2004, V. 1- 2).

Em debates mais específicos, realizados nos diversos fóruns do Processo Sinodal, o verbo amazonizar representou um esforço coletivo para tornar conhecidas as inúmeras experiências de convivência com a Amazônia, tanto no campo como nas cidades. Atualmente, muitas são as instituições preocupadas e empenhadas na busca de meios e possibilidades de uma convivência que retome e dê novos significados à construção de relações humanas baseadas em práticas de cooperação e de participação, buscando alternativas para se viver na lógica da economia solidária, pautada na partilha e na solidariedade, nas relações de convivência, respeito e cuidado com a terra, as águas e as florestas.

A reinvenção do verbo amazonizar foi acrescida de uma provocação à reflexão do tema da internacionalização da Amazônia, tendo por referência os debates levantados durante o processo de escuta do Sínodo para a Amazônia. De fato, o tema da internacionalização da Amazônia não é novo e, frequentemente, vem à tona. De acordo com Medeiros (2012) o termo vem sendo acionado desde 1964. Entretanto, de acordo com este autor,

Há momentos específicos de maior ocorrência, como em 1989 (queda do muro de Berlim e, no Brasil, retomada de eleições diretas para presidente) e, com maior intensidade, em 1991 (CPI da Internacionalização da Amazônia; preparativos para a ECO-92; demarcação da terra indígena Yanomami). Essas relações entre eventos históricos específicos e maior ocorrência da categoria na mídia escrita não são aleatórias, elas indicam que há um vínculo estreito entre leituras específicas sobre a conjuntura internacional e nacional (estratégias militares, mudanças na configuração das potencias econômico-militares, crescimento de propostas ambientais) e novos arranjos político-institucionais nacionais. Essas relações impactam 
diretamente sobre as estratégias de difusão de um modo particular de conceber o território amazônico (MEDEIROS, 2012, p. 129).

A internacionalização apareceu como alternativa dos governos militares quando nossa dívida externa atingia cifras exorbitantes e as estratégias políticas do entreguismo e da privatização pareciam ser a saída para o país. Nos frágeis processos de redemocratização, iniciados em meados da década de 1980, o tema da internacionalização da Amazônia continuava em pauta em recorrentes pronunciamentos em eventos internacionais. Entretanto, desde os primórdios da colonização, os povos dessa imensa região enfrentam as piores investidas internacionais sobre seu território e procuram resistir de forma coesa e organizada. De maneira especial, os inúmeros povos indígenas têm se posicionado em defesa da Amazônia e enfrentado todo tipo de violência e opressão por causa da luta em defesa da Ecologia Integral nesta grande casa comum.

A resistência à internacionalização da Amazônia e a defesa da soberania de seus povos se fez muito presente nos relatórios das escutas sinodais em diversos grupos e fóruns de discussão. Em praticamente todos os relatórios das escutas, desde as rodas de conversa, passando pelas Assembleias Territoriais e chegando até os seminários e fóruns temáticos, os clamores dos povos da Amazônia se fizeram ouvir em defesa do ordenamento de seus territórios, especialmente os territórios tradicionais, apelando pela racionalidade do uso dos recursos naturais, de acordo com a proposta da Ecologia Integral, comprovada na vivência dos povos tradicionais (OLIVEIRA, 2019).

Nessa conjuntura, os povos da Amazônia propõem a amazonização do mundo e não a internacionalização da Amazônia (HECK; LOEBENS; CARVALHO, 2005). Por isso, amazonizar encontra-se estreitamente relacionado com a proposta da Ecologia Integral, que se faz presente nas práticas de cultivo e coleta de recursos naturais, que são baseadas no cuidado e no respeito pela natureza como parte da vivência coletiva. Para os povos indígenas, camponeses, afrodescendentes, quilombolas, seringueiros, ribeirinhos, pescadores, ambientalistas e gente simples das periferias das cidades, a Amazônia representa a casa comum de todos os povos. Na casa comum, todos e todas vivem do resultado do trabalho cotidiano, sem acumulação e sem exclusão. Isso é amazonizar.

Por fim, o modelo de sociedade baseado na Ecologia Integral desafia a sociedade a se deixar amazonizar, para amazonizar as cidades, o coração da Igreja e dos governantes, e o mundo inteiro. Neste sentido, amazonizar é o projeto que se contrapõe a um modelo 
desenvolvimentista. Significa garantir os direitos humanos dos povos que vivem e convivem diariamente com as florestas, rios e lagos sem desmatar, queimar ou contaminar. Significa um modo de vida que garanta direitos e dignidade para todas as pessoas num modelo de sociedade includente, justo e fraterno. Por tudo isso, amazonizar é o verbo do tempo presente assimilado, reconhecido e retomado no processo sinodal. O coração da Igreja deixou-se amazonizar pelo texto base que orientou a primeira etapa do processo sinodal posteriormente sistematizado no Instrumentum Laboris (2019).

\section{As migrações no documento final da Assembleia sinodal}

Do Sínodo para a Amazônia, adquirimos a habilidade do diálogo e discernimento e fomos chamados à conversão integral, considerando quatro dimensões: a cultural, a ecológica, a sinodal e a pastoral.

O Documento Final da Assembleia Sinodal(2019) que inspira a escrita da Exortação Apostólica "Querida Amazônia", assinada pelo Papa Francisco e publicada em 12 de fevereiro de 2012, exorta, desde o início, a uma "verdadeira conversão integral", comprometida em relacionar-se harmoniosamente com a "Casa comum", obra criativa de Deus. Essa conversão levará a Igreja a ser em saída, para entrar no coração de todos os povos amazônicos, considerando a realidade multiétnica e multicultural da região.

Na primeira parte, o Documento Final da Assembleia Sinodal acena para a realidade migratória em toda Pan-Amazônia. A mobilidade humana (INSTRUMENTUM LABORIS, 2019, cap. III), característica do mundo atual (DAp, 207, p. 231), representa o mais vasto movimento de pessoas de todos os tempos, denuncia as desigualdades sociais produzidas na estrutura do atual sistema econômico e revela uma complexa realidade social, cultural, política, econômica, religiosa e pastoral (INSTRUÇÃO ERGA MIGRANTES CARITAS CHRISTI, 2004). "Não se trata apenas de migrantes. Trata-se da pessoa toda e de todas as pessoas" 6 .

As migrações denunciam as injustiças e desigualdades sociais, a centralização das riquezas, o desemprego, o processo crescente de empobrecimento, a violação aos direitos humanos, a mercantilização dos recursos naturais, a atuação dos grandes projetos economicistas que se instalam na região através das grandes mineradoras, das hidroelétricas,

\footnotetext{
6 Tema do Dia mundial dos Migrantes e Refugiados 2019.
} 
das petroleiras transnacionais, das corporações do agronegócio e, acima de tudo, a centralização dos bens e serviços nas grandes cidades (LIMA; POZZOBON, 2005).

O Documento Final da Assembleia Sinodal esclarece que, na Pan-Amazônia, vivenciase três processos migratórios simultâneos: as migrações internas caracterizadas pelos deslocamentos, eminentemente compulsórios, de povos indígenas e camponeses para as cidades; as migrações inter-regionais que deslocam pessoas entre os países da região e por toda América Latina; ao mesmo tempo, é uma região que exporta migrantes para outros continentes. Também a questão do refúgio tem emergido com grande ênfase num contexto marcado pela violência institucional que caracteriza os processos de expulsão7.

A mobilidade humana na Pan-Amazônia revela o rosto de Cristo empobrecido (Mt 25, 35), faminto (Mt 25,36), expulso e sem lugar (LC 3, 1-3). Os migrantes circulam por todo por todo continente latino-americano e nos fazem recordar o importante preceito bíblico: "meu pai era um arameu errante" (Dt 26,5). Revelam, também, o rosto de Maria na feminização das migrações, que tornam milhares de mulheres vulneráveis ao tráfico humano, uma das piores formas de violência contra as mulheres e uma das mais perversas violações aos direitos humanos (OLIVEIRA, 2016, p. 69). "A escravidão moderna em todas as suas formas, prostituição, trabalho forçado, mutilação, venda de órgãos ou trabalho infantil, é um crime de lesa humanidade" ${ }^{\prime 8}$. O tráfico humano encontra-se estreitamente vinculado às migrações e exige um trabalho pastoral articulado em rede, com ênfase na prevenção, defesa e proteção das vítimas (OLIVEIRA, 2016, p. 167).

Os deslocamentos forçados de grupos indígenas (INSTRUMENTUM LABORIS, 2019, n. $45,46,53,63,64,65,129,146)$, expulsos de seus territórios, representam uma especificidade singular dos movimentos migratórios. Nos casos em que a mobilidade destes grupos ocorra em territórios de circulação tradicional indígena, separados por fronteiras nacionais, torna-se necessária uma pastoral de conjunto transfronteiriça, articulada pela Pastoral Indigenista, capaz de compreender o direito à livre circulação destes povos, garantindo sempre a efetivação dos direitos contemplados nos instrumentos internacionais como a Convenção 169 da OIT.

\footnotetext{
7 Como o que vem ocorrendo na Venezuela desde 2014.

${ }^{8}$ Papa Francisco (2014) no discurso de assinatura do Acordo com líderes de várias confissões para erradicar a escravatura até 2020 .
} 
O atual contexto migratório indica que os caminhos pastorais passam pela articulação em redes de pastorais de conjunto com novas modalidades de colaboração entre as igrejas locais, as Conferências Episcopais, institutos missionários e pastorais, entidades de cooperação fraterna, o diálogo e parceria com as agências nacionais e internacionais dedicadas aos migrantes.

A grande maioria dos migrantes e refugiados concentra-se nas periferias das cidades da Pan-Amazônia, nas quais a Igreja, através de seus organismos e pastorais, se posiciona na contramão da xenofobia e de todas as formas de discriminação e criminalização dos migrantes, mobilizando-se para acolher, compartilhar, cuidar e integrar os migrantes e refugiados que são tratados como um "lixo humano que nem as empresas, nem os sistemas políticos, nem os grandes líderes econômicos estão interessados em reciclar" ${ }^{\prime \prime}$. Desta forma, os migrantes e os refugiados redefinem e reposicionam a pastoral nos centros urbanos da Amazônia, desafiada a responder aos grandes desafios da crescente urbanização (DAp, n. $517, A)$.

Diante deste contexto, o Documento Final da Assembleia Sinodal nos convida a prestar atenção ao deslocamento forçado de famílias indígenas nos centros urbanos, e sugere a criação de equipes missionárias que, em coordenação com as paróquias, cuidem desse povo, oferecendo liturgias inculturadas e favorecendo a integração dessas comunidades nas cidades.

\section{A conversão integral e suas quatro dimensões}

A Conversão Integral, sugerida no Documento Final da Assembleia Sinodal, possui quatro dimensões. A primeira é a Conversão Pastoral que aponta que a ação missionária é o paradigma de toda obra da Igreja e o diálogo é o único meio evangélico para "propor" e não "impor" a Boa Nova do Reino de Deus. E, para acolher o outro, só uma Igreja samaritana, misericordiosa e solidária será capaz de escutar e aprender com os diferentes (Jo 4, 7-26. 2830.39-42; LC 10,29-37).

O Documento Final da Assembleia Sinodal recorda os muitos missionários que deram a vida para transmitir o Evangelho na Amazônia e enfatiza que a Igreja tem "a oportunidade

\footnotetext{
9 Papa Francisco: Campanha Compartilha a viagem, 2017.
} 
histórica" de se distanciar das novas potências colonizadoras, ouvindo os povos amazônicos e exercendo sua atividade profética "de forma transparente".

O diálogo ecumênico e inter-religioso foi considerado o "Caminho indispensável da evangelização na Amazônia". Diante disso, o Documento Final da Assembleia Sinodal incentiva um maior conhecimento das religiões indígenas e dos cultos afrodescendentes, a fim de que todos possam agir juntos em defesa da Casa comum. Manter "uma opção preferencial pelas populações indígenas", dando, também, maior impulso missionário às vocações autóctones, dar espaço aos jovens amazônicos, e promover novas formas de evangelização através das mídias sociais são propostas.

A defesa do direito de todos à cidade como desfrute justo dos princípios de sustentabilidade, democracia e justiça social é ressaltado. As Comunidades Eclesiais de Base são consideradas "um presente de Deus para as Igrejas locais da Amazônia".

A segunda conversão refere-se à Conversão Cultural. Esta ocupa uma parte importante da Exortação Apostólica "Querida Amazônia". Dada sua relevância, a dimensão cultural foi um tema muito debatido e aprofundado durante todo processo sinodal que reconheceu que vivemos num território de inúmeros povos, muitos deles milenares e portadores de ancestralidades e costumes que definem um jeito próprio de ser e de viver nesta imensa região.

A Conversão Cultural é apresentada como um compromisso e uma atitude de permanente aprendizagem que implica "fazer-se o/a outro/a, aprender do/a outro/a", conviver com o/a outro/a, respeitar suas diferenças, reconhecer seus valores, viver e praticar a inculturação e a interculturalidade no anúncio da Boa Nova que "se faz carne e arma sua tenda na Amazônia". De acordo com o documento, "somente uma Igreja missionária inserida e inculturada fará emergir Igrejas particulares autóctones, com rosto e coração amazônicos, enraizadas nas culturas e tradições próprias dos de seus povos, unidas na mesma fé em Cristo e diversas em seu modo de vivê-la, expressá-la e celebrá-la".

A diversidade cultural dos povos da Amazônia aponta para a possibilidade de uma convivência fraterna fundamentada na reciprocidade, na solidariedade, no sentido de comunidade, na igualdade de direitos e participação, reconhecendo que "tudo está interligado nesta casa comum". Uma Igreja inculturada assume a defesa da vida, da comunidade, da terra e dos direitos dos seus povos. É uma Igreja que rompe com o pensamento e as práticas neocolonialistas, que rejeita o clericalismo e assegura uma 
catequese apropriada para acompanhar os processos de iniciação cristã que conduzem à vivência do mistério da fé refletido em uma teologia inculturada que promove a vida da Igreja com identidade e rosto amazônicos.

A Conversão Cultural abre caminhos para uma cultura comunicativa, que favorece o diálogo, a cultura do encontro e o cuidado da "casa comum" à luz dos valores da ecologia integral e do "bem viver", que colocam em marcha uma sociedade mais justa e fraterna. A Conversão Cultural nos leva a investir cada vez mais na construção da cultura da paz no campo e nas cidades, a rejeitar as armas, os discursos e as práticas autoritárias, a promover uma Igreja capaz de acolher e integrar os migrantes, os indígenas, os negros quilombolas, os jovens com suas identidades diversas, os pobres e excluídos/as, o protagonismo das mulheres, dos operários e dos desempregados. Por fim, convida-nos a repensar nosso consumismo individualista e investir em cidades sustentáveis, políticas públicas participativas e democráticas, economias solidárias e compartilhadas.

O Sínodo considerou que a inculturação e a interculturalidade são instrumentos importantes para alcançar uma conversão cultural. A Igreja compromete-se a ser aliada das populações indígenas, para denunciar os ataques contra suas vidas, os projetos de desenvolvimento predatórios etnocidas e ecocidas e a criminalização dos movimentos sociais.

O respeito dos direitos à autodeterminação, à delimitação dos territórios e à consulta prévia, livre e informada dos povos indígenas, é enfatizada e é dedicada especial atenção às populações indígenas em isolamento voluntário e recomenda-se que a Igreja deve empreender dois tipos de ação: pastoral e outra "de pressão", para que os Estados protejam os direitos e a inviolabilidade dos territórios dessas populações. Há clara rejeição de uma "evangelização colonial" e do "proselitismo", em favor de um anúncio inculturado que promova uma Igreja de rosto amazônico, em respeito à cultura e ao estilo de vida das populações locais. Há também um forte apelo à cultura da comunicação que promova o diálogo, o encontro e o cuidado da casa comum.

A terceira conversão é a ecológica. O Documento Final da Assembleia Sinodal reconhece que a Ecologia Integral é o único caminho possível para conectar o cuidado pastoral da natureza à justiça para com as pessoas mais pobres e exploradas da terra e salvar a região amazônica do extrativismo predatório, do derramamento de sangue inocente e da criminalização dos defensores da Amazônia. A Igreja, como "parte de uma solidariedade 
internacional", deve promover o papel central do bioma amazônico para o equilíbrio do planeta e encorajar a comunidade internacional a fornecer novos recursos econômicos para sua proteção.

Defender e promover os direitos humanos e denunciar a violação dos direitos humanos e a destruição extrativista são vistos como primordiais no Sínodo, que assume e apoia, também em aliança com outras Igrejas, as campanhas de desinvestimento das empresas extrativistas que causam danos sociais e ecológicos à Amazônia; propõe uma transição energética radical e a busca de alternativas, propõe, também, o desenvolvimento de programas de formação para o cuidado da "casa comum". Apela a um "novo paradigma de desenvolvimento", justo e solidário.

A Conversão Ecológica reconhece a sabedoria dos povos sobre a biodiversidade e o conhecimento tradicional é valorizado e respeitado. Pede-se que os agentes pastorais e os ministros ordenados sejam formados com esta sensibilidade socioambiental, seguindo o exemplo dos mártires da Amazônia e propõe-se criar ministérios para o cuidado da casa comum. O Documento reafirma o empenho da Igreja em promover o diálogo intercultural e ecumênico para conter as estruturas de morte, pecado, violência e injustiça.

O Documento Final da Assembleia Sinodal propõe a definição de "pecado ecológico" como "ação ou omissão contra Deus, contra o próximo, a comunidade, o meio ambiente" (INSTRUMENTUM LABORIS, 2019, p. 59). O pecado ecológico tem diversas características que atentam contra a vida das pessoas, da fauna, da flora e de todo o planeta ${ }^{10}$. O uso indiscriminado de agrotóxicos para produção de alimentos é um grave pecado ecológico. Trata-se de uma prática muito usual nas empresas do agronegócio em toda Pan-Amazônia. Os agrotóxicos contaminam a terra, o ar e as águas, os alimentos que serão ingeridos, inclusive por crianças, iniciando processos de adoecimento e morte.

Pecado Ecológico também é a prática da exploração dos recursos minerais de forma predatória e irresponsável. Um garimpo irregular, por exemplo, por mais pequeno que seja, utiliza mercúrio que contamina a terra e as águas que abastecem comunidades inteiras na

\footnotetext{
${ }^{10}$ Fragmentos deste debate são apresentados no artigo intitulado "o Sínodo da Amazônia, a religião e o meio ambiente" que afirma que a possibilidade da instituição do pecado ecológico gerou muita tensão na Assembleia Sinodal. Os endinheirados, que se sentem incomodados com o pecado ecológico, resolveram usar a mídia subalterna para desqualificar o Sínodo e se colocar contra o Papa Francisco. Artigo disponível em: Link Acesso em: 9 jan., 2019.
} 
Amazônia, especialmente territórios indígenas e quilombolas. Em pouco tempo, populações humanas inteiras começam a apresentar sintomas da contaminação tais como doenças na pele, diversos tipos de câncer, perda da visão. E logo vem a morte. A exploração mineral desmedida, de forma predatória e irresponsável como aquela de Mariana e Brumadinho em Minas Gerais, que enterrou vivas centenas de pessoas, também se faz presente em toda PanAmazônia e é pecado mortal que faz circular economias imensuráveis às custas da vida de tantas pessoas. Como toda forma de pecado, o ecológico incomoda quem o pratica porque sabe que está agindo, ética e moralmente, contrário aos valores evangélicos que professa.

Para reparar a dívida ecológica que os países têm com a Amazônia, sugere-se a criação de um fundo mundial para as comunidades amazônicas, a fim de protegê-las do desejo predatório das empresas nacionais e multinacionais. O Documento Final da Assembleia Sinodal aponta uma série de ações voltadas para a melhoria das condições de vida na Terra no Antropoceno, como a necessidade de reduzir drasticamente as emissões de dióxido de carbono e de outros gases ligados à mudança climática, de promover fontes de energia limpa, de dar acesso à água potável, de incentivar a reutilização e a reciclagem, reduzir o uso de combustíveis fósseis e plásticos, mudar hábitos alimentares e adotar estilos de vida sóbrios e plantar árvores, dentre inúmeras outras práticas ecológicas. Para acompanhar as mudanças que se processarão foi proposta a criação de um Observatório Social Pastoral Amazônico ainda a ser pensado na sua operacionalidade.

A quarta conversão proposta no Documento Final da Assembleia Sinodal é a Conversão Sinodal. Ela evoca o permanente exercício da sinodalidade. Fundamentada na Constituição Apostólica Episcopalis Communion - sobre o sínodo dos bispos (2017), assinada pelo Papa Francisco, a Conversão Sinodal assinala que a sinodalidade é a dimensão de comunhão participativa de toda a Igreja.

Embora na sua composição se configure como um organismo essencialmente episcopal, o Sínodo não vive separado do resto dos fiéis. Pelo contrário, é um instrumento adequado para dar voz a todo o Povo de Deus precisamente por meio dos Bispos, constituídos por Deus como autênticos guardiões, intérpretes e testemunhas da fé de toda a Igreja, mostrando-se de Assembleia em Assembleia uma expressão eloquente da sinodalidade como dimensão constitutiva da Igreja (EPISCOPALIS COMMUNION, 2017, n. 6).

Na perspectiva da sinodalidade, a Conversão Sinodal nasce na experiência do sínodo, que tem o objetivo de garantir ser descentralizado, atento aos processos locais, sem 
enfraquecer o elo com as Igrejas irmãs e com a Igreja universal. A sinodalidade se traduz em continuidade com o Concílio Vaticano II, em corresponsabilidade e ministerialidade de todos, participação dos leigos, homens e mulheres, considerados "atores privilegiados" (Jo 15,1415).

A sinodalidade aposta na participação do laicato, seja na consulta, seja na tomada de decisões na vida e missão da Igreja, que deve ser reforçada e ampliada a partir da promoção e concessão de ministérios a homens e mulheres de forma justa e equitativa.

O Documento Final da Assembleia Sinodal, em sua parte final, aposta numa Vida Consagrada com rosto amazônico, a partir de um reforço das vocações e o caminhar junto aos pobres e excluídos. Pede-se, ainda, que a formação seja centrada na interculturalidade, inculturação e diálogo entre as espiritualidades e as cosmovisões amazônicas.

Uma atenção especial é dada ao protagonismo das mulheres na Igreja da Amazônia. Pede-se que a voz das mulheres seja ouvida, que sejam consultadas, participem de modo mais incisivo na tomada de decisões, contribuam para a sinodalidade eclesial, assumam com maior força sua liderança dentro da Igreja. O Sínodo evidencia que, em inúmeras consultas na Amazônia, foi solicitado "o diaconato permanente para as mulheres". O tema foi colocado em pauta e se sugeriu aguardar os resultados da "Comissão de estudo sobre o diaconato das mulheres", criada em 2016 pelo Papa Francisco.

A promoção, a formação e o apoio aos diáconos permanentes foi enfatizada de modo contundente. O Documento Final da Assembleia Sinodal os encarrega de promover a ecologia integral, o desenvolvimento humano, a pastoral social e o apoio a pessoas em situações de vulnerabilidade e pobreza. Encoraja a formação de futuros diáconos permanentes nas comunidades longínquas e no âmbito da formação ao sacerdócio, propōe a inclusão de disciplinas como a ecologia integral, a ecoteologia, a teologia da criação, as teologias indígenas, a espiritualidade ecológica, a história da Igreja na Amazônia, a antropologia cultural amazônica, inseridas na realidade amazônica.

Reconhecendo como central a participação à Eucaristia na comunidade cristã, e as dificuldades de acesso a ela, na Amazônia, o Documento Final da Assembleia Sinodal propõe "estabelecer critérios e regras por parte da autoridade competente, para ordenar sacerdotes reconhecidos pela comunidade para promover a vida da comunidade cristã através da pregação da Palavra e da celebração dos sacramentos nas áreas mais remotas da região 
amazônica". Garantindo, desta forma, que se cumpra o mandato evangélico de uma Igreja de presença junto às comunidades mais distantes e menos desassistidas.

O Documentos Sinodal propõe, ainda, a criação de um organismo eclesial regional pós-sinodal, que assuma muitas das propostas do Sínodo. É proposta a formação de uma Universidade Católica Amazônica, baseada na pesquisa interdisciplinar, na inculturação e no diálogo intercultural. Sugere-se, também, a constituição de uma comissão para estudar a elaboração de um rito amazônico que "expresse o patrimônio litúrgico, teológico, disciplinar e espiritual da Amazônia", a fim de enriquecer a obra de evangelização da Igreja e a capacidade de expressar a fé numa cultura própria.

\section{Os dez mandamentos do Sínodo Especial para a Amazônia}

A partir do Documento Final da Assembleia Sinodal, extraímos a essência dos resultados obtidos no Sínodo para apontar o que denominamos "Os Dez Mandamentos do Sínodo para a Amazônia", numa referência ao decálogo bíblico que estabeleceu uma relação de reciprocidade entre Deus e a humanidade, numa aliança firmada de forma voluntária e alegre. Uma aliança que exigiu outrora e exige, agora, compromisso e responsabilidades ${ }^{11}$.

Os Dez Mandamentos do Sínodo representam um conjunto de propostas elaboradas a partir de nossa síntese dos conteúdos que se sobressaíram na Assembleia Sinodal e nos círculos menores:

10 Mandamento: Amazonizarás a Igreja de forma a acolher as culturas e tradições amazônicas como expressão do Espírito de Deus que conduz os povos e a vida;

$2^{\circ}$ Mandamento: Defenderás os direitos dos mais vulneráveis (e da natureza) e fortalecerás a luta em defesa da vida, da justiça e dos direitos humanos;

$3^{\circ}$ Mandamento: Terás consciência da dramática situação de destruição que afeta a Amazônia e seus povos;

${ }^{11}$ O Decálogo apresentado em Êxodo 20, 1-17 é o tema central e mais exaltado deste livro. O que foi registrado antes era preparação para ele; e tudo que foi registrado depois dele é resultado e suplemento. Estabelece códigos de convivência entre os irmãos e na relação com Deus, num contexto marcado pela busca de um Deus que se faz presença e caminha junto com seu povo. 
$4^{\circ}$ Mandamento: Não pecarás contra as gerações futuras em atos e hábitos de contaminação e destruição da harmonia do meio ambiente amazônico;

$5^{\circ}$ Mandamento: Buscarás mudanças radicais e urgentes em direção a um modelo de existência social e de relação com a natureza que permita salvar a Amazônia, garantir o Bem Viver e a convivência com o Bioma;

$6^{\circ}$ Mandamento: Reconhecerás com admiração e protegerás aqueles e aquelas que lutam, com grande risco de suas próprias vidas, para defender o território e o povo amazônico;

$7^{\circ}$ Mandamento: Assumirás o diálogo ecumênico, inter-religioso e intercultural como o caminho irrevogável da evangelização na Amazônia.

$8^{\circ}$ Mandamento: Fortalecerás e renovarás os Ministérios Leigos, a Vida Consagrada, o presbiterato e o diaconato, com identidade amazônica, fortalecendo as vocações autóctones e priorizando uma missão pautada numa presença constante, numa escuta atenta e no compromisso com a libertação;

9 Mandamento: Ouvirás as vozes das mulheres para tomar decisões e contribuir com sua sensibilidade à sinodalidade eclesial, reconhecendo e valorizando o seu protagonismo no cuidado com a Casa Comum;

10 Mandamento: Viverás uma Igreja em saída, pautada na sinodalidade, comprometida com a defesa da vida na Amazônia e para a Amazônia.

Muitos outros compromissos poderiam somar-se nesta grande aliança no processo pós-sinodal que nos convida a "caminhar juntos/as" (sinodalidade), trilhando os "novos caminhos para a Igreja e para uma Ecologia Integral" na nossa "querida Amazônia".

\section{Considerações finais}

O Sínodo dos Bispos ou a Assembleia Especial para a Região Pan-Amazônica representa um divisor de águas na história da Igreja na Amazônia. Enseja um tempo oportuno para amazonizar o coração da Igreja e de toda humanidade e provocar mudanças importantes para a construção de novos caminhos de uma Igreja com rosto amazônico.

A Assembleia Sinodal e o Documento Final representam a chegada da periferia ao centro, uma mudança no lugar de fala. Os povos marginalizados das periferias do mundo 
chegaram a Roma e se fizeram ouvir. Os clamores do sofrimento de todos os povos da Amazônia ecoaram em Roma, na Cidade do Vaticano, entre os dias 06 a 27 de outubro de 2019. Foi a primeira vez que tantas mulheres adentraram a Sala Sinodal, ocuparam seus assentos e se fizeram ouvir e apresentaram as demandas de suas coletividades com autoridade científica, bíblica, teológica, eclesiológica e política, "sem perder a ternura jamais".

Foi um sínodo especial porque soube acolher e envolver, no processo sinodal, os povos indígenas, camponeses, ribeirinhos, as comunidades quilombolas e das reservas extrativistas, os jovens das periferias das cidades, os religiosos e as religiosas inseridos nas comunidades do campo e das cidades.

Com seus corpos, seus cantos e encantos, os povos indígenas se fizeram notar nas ruas de Roma, nos arredores da Basílica São Pedro e na sala sinodal. E se encontraram, por segunda vez, com o Papa Francisco, para recordar o encontro de Puerto Maldonado em janeiro de 2018 e seguir adiante com a garantia de que a Igreja inscreveu, definitivamente, os povos indígenas em sua missão.

Os Dez Mandamentos do Sínodo Especial para a Amazônia foram inspirados neste intenso e extenso processo sinodal. Eles resumem os aspectos mais relevantes que integram a voz da Amazônia com a voz e o sentimento dos participantes do Sínodo. Não obstante, como já foi dito, para atender a esses Dez Mandamentos, não bastam apenas ações individuais, é preciso agir em conjunto, em ações que levem a um comprometimento com o Bem Viver e que promovam a ministerialidade e a sinodalidade capazes de rever outras estruturas da Igreja em harmonia com o cuidado da criação na Amazônia.

Por fim, Os Dez Mandamentos do Sínodo Especial para a Amazônia representam nosso compromisso no cuidado da Casa Comum, expressão de uma Igreja profética, aliada dos povos da Amazônia, em defesa da vida ecológica e espiritual e a serviço do futuro do planeta.

\section{Referências}

BECKER, B. Undoing myths: the Amazon - an urbanized forest. In: CLÜSENERGODT, M.; SACHS, I. (orgs.) Brazilian perspectives on sustainable development for the Amazon region. Paris: UNESCO, v. 15, 1995, p. 53-89. 
DANIEL, Padre João. Tesouro descoberto no máximo rio Amazonas. Apresentação de Vicente Salles. Rio de Janeiro: Contraponto, 2004, Vol. 1- 2.

IGREJA CATÓLICA - Pontifício Conselho para a Pastoral dos Migrantes e Itinerantes. Instrução Erga Migrantes Caritas Christi - A caridade de Cristo para com os migrantes. Documento 15. São Paulo: Paulinas, 2004.

IGREJA CATÓLICA - Papa Bento XVI. Documento de Aparecida. CELAM. Brasília: Edições CNBB, 2007.

IGREJA CATÓLICA - Papa Francisco. Carta Encíclica Laudato Sì: sobre o cuidado da casa comum. Brasília: Edições CNBB, 2015.

IGREJA CATÓLICA - Papa Francisco. Constituição Apostólica Episcopalis Communio.

Documentos Pontifícios n. 36. Brasília: Edições CNBB, 2018.

IGREJA CATÓLICA - Papa Francisco. Documento Preparatório do Sínodo Especial para a Amazônia. Brasília: Edições CNBB, 2018.

IGREJA CATÓLICA - Papa Francisco. Instrumentum Laboris - Documento de Trabalho do Sínodo Especial para a Amazônia. Brasília: Edições CNBB, 2019.

IGREJA CATÓLICA. Síntese Repam. AA.VV., Síntesis general de la red eclesial Panamazónica REPAM - Asambleas Territoriales, Foros Temáticos, Contribuciones especiales y escuchas sobre el sínodo. Quito: Secretaría Ejecutiva de la REPAM, 2019.

GRECHI, Moacir. Mutirão pela Amazônia: espírito missionário e sensibilização da sociedade. In: Pe. Raimundo Possidonio Mata e Ir. Cecília Tada (org). Amazônia, desafios e perspectivas para a missão. São Paulo: Paulinas, 2005. (p. 201-206).

HECK, Egon; LOEBENS, Francisco; CARVALHO, Priscila D. Amazônia indígena: conquistas e desafios. Revista Estudos Avançados, São Paulo, n. 19 (vol. 53), 2005. (p. 237 - 255).

HUMMES, Cláudio. O sínodo para a Amazônia. São Paulo: Paulus, 2019.

LIMA, D.; POZZOBON, J. Amazônia socioambiental, sustentabilidade ecológica e diversidade social. Estudos Avançados 19 (54). p.45-76, 2005

MATA, Raimundo P. A Igreja Católica na Amazônia. Caderno Terceira Margem, Vol 2. N. 6, Jan/Jul. 2016.

MATA, Raimundo P. A Igreja e sua missão na Amazônia. Revista Encontros Teológicos, Santa Catarina, no 46 Ano 22 / número 1/ 2007, p. 19-28.

MEDEIROS, Rodrigo Augusto Lima de. Decodificando a internacionalização da Amazônia em narrativas e práticas institucionais: governos da natureza no Brasil e nos EUA. Tese (Doutorado) Universidade de Brasília, Brasília ICS/CEPPAC, 2012.

OLIVEIRA, Márcia Maria de. Dinâmicas Migratórias na Amazônia Contemporânea. São Carlos: Editora Scienza, 2016. 
OLIVEIRA, Márcia Maria de. Ecoteologia na Amazônia à luz da Laudato Si na trilha dos povos ameríndios. Revista de Ecoteologia, Brasília, Volume 02. 2. ed. novembro de 2017 (p. 13-20).

OLIVEIRA, Márcia Maria. Desafios e perspectivas do processo de preparação do Sínodo Especial para Amazônia. Revista de Cultura Teológica, São Paulo, Ano XXVII, no 94, Jul/Dez 2019 (p. 8-20).

PERANI, Cláudio. A Igreja Na Amazônia: Criatividade, Dinamismo E Vitalidade. Cadernos do CEAS, Salvador, n. $244: 231-241,2018$.

PORRO, João. Um tesouro redescoberto: os capítulos inéditos da Amazônia de Pe. João Daniel. Revista do Instituto de Estudos Brasileiros, São Paulo, n. 43, 2006, p. 127-147

SATHLER, D.; MONTE-MÓR, R. L.; CARVALHO, J. A. M. de. As redes para além dos rios: urbanização e desequilíbrios na Amazônia brasileira. Nova Economia, UFMG, 19(1), 11-39. 2009.

SILVA, H. P. A. Saúde humana e a Amazônia no século XXI: reflexões sobre os objetivos do milênio. Cadernos NAEA, v. 9, n. 1, p. 77-94, jun. 2006.

SOUZA. J. G.; SCHAAN, D. P.; ROBINSON, M. et al. Pre-Columbian earth-builders settled along the entire southern rim of the Amazon. Nature Communications 9 (1), 2018. p.1125.

\title{
Dados dos autores
}

\author{
Ima Célia Guimarães Vieira
}

Possui graduação em Agronomia pela Universidade Federal Rural da Amazônia (1983), mestrado em Genética e Melhoramento de Plantas pela Universidade de São Paulo (1987) e doutorado em Ecologia pela University Of Stirling, Escócia (1996). Foi diretora do Museu Paraense Emilio Goeldi, gestão 2005-2009, presidente do Conselho de Administração do Instituto de Desenvolvimento Sustentável Mamirauá e presidente do Conselho Curador da Empresa Brasil de Comunicação-EBC. Participou do Sinodo Especial para a Amazônia no Vaticano em 2019, à convite do Papa Francisco. Atualmente é membro de comissões do Conselho Nacional de Desenvolvimento Científico e Tecnológico, do Parque Ciência e Tecnologia Guamá e do Fórum de Mudanças Climáticas do estado do Pará. É docente permamente dos programas de pós-graduação da Universidade Federal do Pará e da Universidade Rural da Amazônia, em convênio com o Museu Goeldi e pesquisador titular III - Museu Paraense Emílio Goeldi. Tem experiência na área de Ecologia, com ênfase em Ecologia Aplicada, atuando principalmente nos seguintes temas: Amazônia, ecologia, biodiversidade e restauração florestal. E-mail: ima@museu-goeldi.br ORCID iD: https://orcid.org/0000-0001-5511-0942

\section{Márcia Maria de Oliveira}

Doutora em Sociedade e Cultura na Amazônia ( PPGSCA/UFAM); Pós-Doutorado em Sociedade e Fronteiras (PPGSOF/UFRR); Mestre em Sociedade e Cultura na Amazônia (PPGSCA / UFAM), Mestre em Gênero, Identidade e Cidadania (Universidad de Huelva - Espanha); Cientista Social, Licenciada em Sociologia (UFAM);Professora do Curso de Ciências Sociais da Universidade Federal de Roraima (UFRR); Professora Credenciada do Programa de Pós-Graduação em Sociedade e Fronteiras (PPGSOF/UFRR); Atuação na Formação de Professores (Plano Nacional de Formação de Professores da Educação Básica - PARFOR/UFAM - 2009-2014); Professora do Curso de Ciências Sociais da Universidade Federal do Amazonas (UFAM - 2006-2008); Professora e coordenadora do Curso de Licenciatura em Educação do Campo da Universidade Federal de Rondônia (UNIR - 2015-2018); Coordenadora do Curso de Especialização em Ética e Política (Latu Sensu Iniversidade Católica de Pernambuco - UNICAP/SARES 2006-2010); Pesquisadora do Grupo de Estudo Interdisciplinar sobre Fronteiras: Processos Sociais e Simbólicos (GEIFRON/UFRR);Pesquisadora do Grupo de Estudos Migratórios da Amazônia (GEMA/UFAM); pesquisadora do Observatório das Migrações em Rondônia (OBMIRON/UNIR). Assessora da Rede Eclesial Pan-Amazônica - REPAM/CNBB, da Cáritas Brasileira e do Serviço Pastoral dos Migrantes (SPM). E-mail: marcia.oliveira@unir.br ORCID iD: https://orcid.org/0000-00015511-0942

\section{Raimundo Posidônio Carrera da Mata}

Mestre em História da Igreja (Gregoriana Roma). Especialista em História da Igreja na América Latina e Brasil pela PUC São Paulo. Filosofia e Teologia no Instituto Regional de Pastoral (Ipar) e Universidade Federal do Pará (Ufpa). Professor de História da Igreja, Religiosidade Popular, Ecumenismo e Cultura Religiosa.Faculdade Católica de Belém - FACBEL. E-mail: monsenhorcid@gmail.com 